\title{
AEGIS: a wildfire prevention and management information system
}

\author{
Kostas Kalabokidis $^{1}$, Alan Ager ${ }^{2}$, Mark Finney ${ }^{2}$, Nikos Athanasis ${ }^{1}$, Palaiologos Palaiologou ${ }^{1}$, and Christos Vasilakos ${ }^{1}$ \\ ${ }^{1}$ University of the Aegean, Department of Geography, University Hill, 81100 Mytilene, Lesvos, Greece \\ ${ }^{2}$ USDA Forest Service, Rocky Mountain Research Station, Missoula Fire Sciences Laboratory, 5775 Hwy 10 West, Missoula, \\ Montana 59808, USA
}

Correspondence to: Kostas Kalabokidis (kalabokidis@aegean.gr)

Received: 9 September 2015 - Published in Nat. Hazards Earth Syst. Sci. Discuss.: 12 October 2015

Revised: 12 February 2016 - Accepted: 22 February 2016 - Published: 4 March 2016

\begin{abstract}
We describe a Web-GIS wildfire prevention and management platform (AEGIS) developed as an integrated and easy-to-use decision support tool to manage wildland fire hazards in Greece (http://aegis.aegean.gr). The AEGIS platform assists with early fire warning, fire planning, fire control and coordination of firefighting forces by providing online access to information that is essential for wildfire management. The system uses a number of spatial and non-spatial data sources to support key system functionalities. Land use/land cover maps were produced by combining field inventory data with high-resolution multispectral satellite images (RapidEye). These data support wildfire simulation tools that allow the users to examine potential fire behavior and hazard with the Minimum Travel Time fire spread algorithm. End-users provide a minimum number of inputs such as fire duration, ignition point and weather information to conduct a fire simulation. AEGIS offers three types of simulations, i.e., single-fire propagation, point-scale calculation of potential fire behavior, and burn probability analysis, similar to the FlamMap fire behavior modeling software. Artificial neural networks (ANNs) were utilized for wildfire ignition risk assessment based on various parameters, training methods, activation functions, pre-processing methods and network structures. The combination of ANNs and expected burned area maps are used to generate integrated output map of fire hazard prediction. The system also incorporates weather information obtained from remote automatic weather stations and weather forecast maps. The system and associated computation algorithms leverage parallel processing techniques (i.e., High Performance Computing and Cloud Computing) that ensure computational power required for real-time application. All AEGIS functionalities are accessible to authorized end-users through a web-based
\end{abstract}

graphical user interface. An innovative smartphone application, AEGIS App, also provides mobile access to the webbased version of the system.

\section{Introduction}

Weather, topography and fuel patterns along with socioeconomic conditions are all factors that contribute to the complexity and uncertainty of wildfire risk management. Expected impacts of climate change, including global increases in wildfire severity and frequency, further complicate the wildfire management problem (Abatzoglou and Kolden, 2013; Kalabokidis et al., 2015). Decision support systems are increasingly being developed and applied in a number of different capacities to improve firefighter protection, develop tactical firefighting strategies, analyze landscape fuels reduction programs, and provide for environmental protection (Ager et al., 2011; Kalabokidis, 2004; Miller and Ager, 2013; Noonan-Wright et al., 2011). Acquired knowledge from these information systems gives fire protection agencies the ability to spatially define and identify high-risk areas, in the short- and long-term, and plan the necessary preventive and control actions as part of a wildfire risk governance system (Miller and Ager, 2013; Taylor et al., 1997).

There are many challenges associated with building and deploying wildfire decision support tools. Ideally, an integrated wildfire prevention and management system should provide instant access to functionalities such as fire danger forecasts, fire behavior prediction, active fire detection, access to historical fire data and fire damage assessment. In terms of usability, such a system should be fairly intuitive, so that end-users can utilize it without specialized knowledge 
on performing fire science related modeling. From an implementation standpoint, the system must have the capacity and reliability to meet the real-time demands users pose during the peak wildfire season without excessive requirements for maintenance.

Tailor-made wildfire decision support systems have been developed and used in a number of different wildfire regions, including Spain (Alonso-Betanzos et al., 2003), France (Figueras Jové et al., 2014), Italy (Losso et al., 2012), Turkey (Gumusay and Sahin, 2009), the US (Noonan-Wright et al., 2011), and in the alpine areas of Europe (Corgnati et al., 2008). Despite the large number of systems, few of them can be considered fully integrated solutions to the wildfire management problem, and generally each of the aforementioned systems has emphasized a specific functionality.

A good example where integration of fire management systems has not been emphasized is in Greece, where the firefighting strategy has relied on a string of independent software and systems that are used separately to accomplish simple operational needs. These systems include Google Earth for mapping and data handling, the European Forest Fire Information System (EFFIS, San-Miguel-Ayanz et al., 2002) for current situation assessment (especially for post-wildfire burned area estimation), Google Maps on custom web applications for wildfire events registration, and Geographic Information System (GIS) tools to map daily fire risk from the General Secretariat for Civil Protection (GSCP) ${ }^{1}$. This wildfire management scheme in Greece evolved from many previous efforts that included both conceptual papers and applied studies. For instance, Iliadis (2005) and Kaloudis et al. (2008) introduced theoretical approaches regarding wildfire prevention and management systems in Greece, but the ideas were never implemented. On the practical side, applications developed by Caballero (1998), Vakalis et al. (2004) and Kalabokidis et al. (2012) resulted in stand-alone systems that were difficult to use due to requirements for local installations of specific software components. The first attempt to develop a fully integrated and distributed system for Greece was Virtual Fire (Kalabokidis et al., 2013a), a web-based GIS platform designed to deliver a wide range of forest fire related information. It provided spatial fire ignition probability estimation (Vasilakos et al., 2007, 2009), visualization of weather forecast maps, real-time weather data from Remote Automatic Weather Stations (RAWS) and fire management tools (e.g., fleet tracking, routing, closest facilities and RSS feeds). While overcoming many integration and implementation shortcomings of previous systems, key functionality of fire behavior simulations could be conducted only with the assistance of a system administrator. The application consisted of two high-performance computing (HPC) nodes for the spatial calculations, while dependent on commercial ArcGIS $^{2}$ software for spatial data visualization and support of

\footnotetext{
${ }^{1}$ http://civilprotection.gr/en

2 www.esri.com
}

geo-processing tasks. The financial cost to maintain/operate the system on-premises was significant, even though the system had been applied for a relatively small area of about $1600 \mathrm{~km}^{2}$ (i.e., Lesvos, Greece). This platform evolved into the VENUS-C system (Kalabokidis et al., 2014b) consisting of a wildfire risk and wildfire spread simulation service, delivered within a web-based interactive platform to the fire management agencies as Software as a Service (SaaS) in the Cloud Computing platform of Microsoft Azure. The wildfire risk service generated hourly maps of the forecasted fire risk for the next $112 \mathrm{~h}$ in high spatiotemporal resolution based on forecasted meteorological data. In addition, actual fire risk was calculated hourly, based on meteorological conditions provided by RAWS. Regarding the wildfire behavior simulation service, end-users were able to simulate fire spread by simply providing an ignition point and the duration of the simulation, based on the HFire algorithm (Peterson et al., 2009). The instant and prompt availability of processing power, along with the cost effectiveness, reliability and scalability of the Azure Cloud were the main advantages of the VENUS-C system.

Outside of Greece, parallel efforts to develop universal fire management decision support tools resulted in a number of other decision support systems. In the European Union, the EFFIS system was developed to support forest protection against wildfires for over 30 countries in the European and Mediterranean regions (San-Miguel-Ayanz et al., 2002). EFFIS is considered a comprehensive system covering the full cycle of forest fire management, from forest fire prevention and preparedness to post-fire damage analysis. The services include Fire Weather Index (FWI) forecasts, active fire detection through MODIS satellites, rapid damage assessment and post-fire modules dealing with the analysis of land cover damages, post-fire soil erosion, emissions estimates and dispersion of the smoke plume, and finally the monitoring of vegetation recovery in large burned areas. EFFIS estimates fire danger based on the Canadian FWI (Van Wagner, 1987), while weather forecast data are provided by Meteo France $^{3}$ and DWD (Deutcher Wetterdienst) ${ }^{4}$.

Comprehensive wildfire management systems were also built in the US and Canada. A strategic and tactical suppression system was built in the US (Wildland Fire Decision Support System, WFDSS) (Noonan-Wright et al., 2011) that is widely used for incident support. WFDSS assists fire managers and analysts in making strategic and tactical decisions for fire incidents with a system that is easy to use, intuitive, linear, scalable and progressively responsive to changing fire complexity. WFDSS uses the National Fire Danger Rating System (NFDRS) (Burgan, 1988) for fire danger estimation, while data from RAWS (Zachariassen et al., 2003) are utilized for weather analysis. Potential wildfire spread from existing ignitions is forecasted for a maximum

\footnotetext{
${ }^{3}$ www.meteofrance.com

${ }^{4}$ www.dwd.de
} 
of 10 days using the Minimum Travel Time (MTT) algorithm (Finney, 2002) embedded within the FSPro simulation software (Finney et al., 2011a; McDaniel, 2016). WFDSS also provides damage assessment for the affected area based on the Rapid Assessment Values at Risk (RAVAR) model (Calkin et al., 2011) and the Stratified Cost Index (Gebert et al., 2007). The WFDSS system is part of a larger family of wildfire simulation models (e.g., FlamMap, FSim, Randig) used by US land management agencies for risk assessment and strategic planning. These systems all implement the MTT algorithm in various wrappers tailored to specific wildfire management problems and associated geographic scales, ranging from continental-scale risk analysis (Finney et al., 2011 b) to watershed-scale (e.g., 5000-50000 ha) fuel treatment projects (Ager et al., 2012). The MTT algorithm models two-dimensional fire growth under constant weather by Huygens' principle where the growth and behavior of the fire edge is modeled as a vector or wave front (Knight and Coleman, 1993). This method reduces distortion of fire perimeters and improves response to temporally varying conditions compared to techniques that model fire growth cell-to-cell on a gridded landscape (Finney, 2002). Perimeter validation has been performed in many studies including Ager et al. (2012) and Salis et al. (2013). A number of support papers have been published on the application of MTT and related models that detail sources of input data, parameters and model limitations (McHugh, 2006; Stratton, 2006; Ager et al., 2011). Extensive documentation on the functionality is contained within the FlamMap5 help system and the functionality can be downloaded and run within the FlamMap5 program ${ }^{5}$. This level of availability of support information and example data sets does not exist with other fire spread models, nor does the code modularity.

In Canada, the Canadian Forest Fire Danger Rating System (CFFDRS) (Lee et al., 2002) is used for predictive services. The CFFDRS comprises two primary subsystems or modules: the Canadian Forest FWI System and the Canadian Forest Fire Behavior Prediction (FBP) system (Forestry Canada Fire Danger Group, 1992; Taylor et al., 1997). Fire monitoring, mapping and modeling is achieved based on high-resolution radiometer (AVHRR) satellite data to detect actively burning forest fires. The Canadian Wildland Fire Information System (CWFIS) (Lee et al., 2002) is Canada's national fire management information system, presenting daily information on fire weather, fire behavior potential and selected upper atmospheric conditions.

In this paper, we describe our efforts to leverage recent technical advances in the systems described above in order to build a comprehensive and easy-to-use web-based decision support tool for fire managers in the Mediterranean region. The result was the wildfire prevention and management information system AEGIS. The system incorporates parallel computer processing techniques utilizing HPC and Cloud

\footnotetext{
${ }^{5}$ www.fire.org
}

Computing resources to enable the rapid execution of spatial fire hazard calculations and fire behavior modeling with the MTT algorithm. Results are made available to users via a robust web-based Graphical User Interface (GUI) and a mobile application (app) that acts as a complementary tool to the web-based version of the system. The system was tested in seven fire-prone study areas across Greece (Fig. 1); i.e., almost $10 \%$ of Greek territory that collectively represents a range of conditions (Table 1) with respect to socioeconomic (i.e., rural/urban interface, population size/density, etc.) and environmental factors (climate, vegetation, topography, geographical distribution, etc.). We describe the core functionality of the AEGIS platform and results from a 3-year development and testing period.

\section{Methodology}

The development of AEGIS required the prior development of the web-based GUI and the corresponding mobile application. Initially, an end-user's requirement analysis was conducted to gather information and knowledge from key stakeholders in the wildfire management community. Subsequently, data collection and field inventories were performed on each of the seven study areas. These data were processed and inserted into geographic databases (one database for each study area) containing all available wildfire management spatial information. The data were used as inputs for the wildfire behavior modeling and hazard rating components of AEGIS. The above-mentioned AEGIS components, along with other relevant information, are described in detail below.

\subsection{End-user's requirement analysis}

Prior to the system's development, we identified key design and functionality features of the system using a formal information gathering process, plus an analysis of the organizational goals and the corresponding processes that should be followed (Athanasis et al., 2015a). This analysis process started with the most generic goal and concluded in determining concrete objectives, the implementation of which led to achieving the overall objectives set out in more generic levels. Each final target was associated with one or more processes. The result of this analysis was a Unified Modeling Language (UML) diagram (Fig. 2) that conceptually represented relationships between goals and corresponding processes. Table 2 presents the proposed services, the identified goals and the corresponding processes to be implemented.

\subsection{Architectural components}

The architectural components of the AEGIS platform are displayed in Fig. 3. The web-based platform of AEGIS was implemented by utilizing the ESRI ArcGIS Application Programming Interface (API) for Silverlight. The API enables the integration of geo-processing and mapping services pro- 


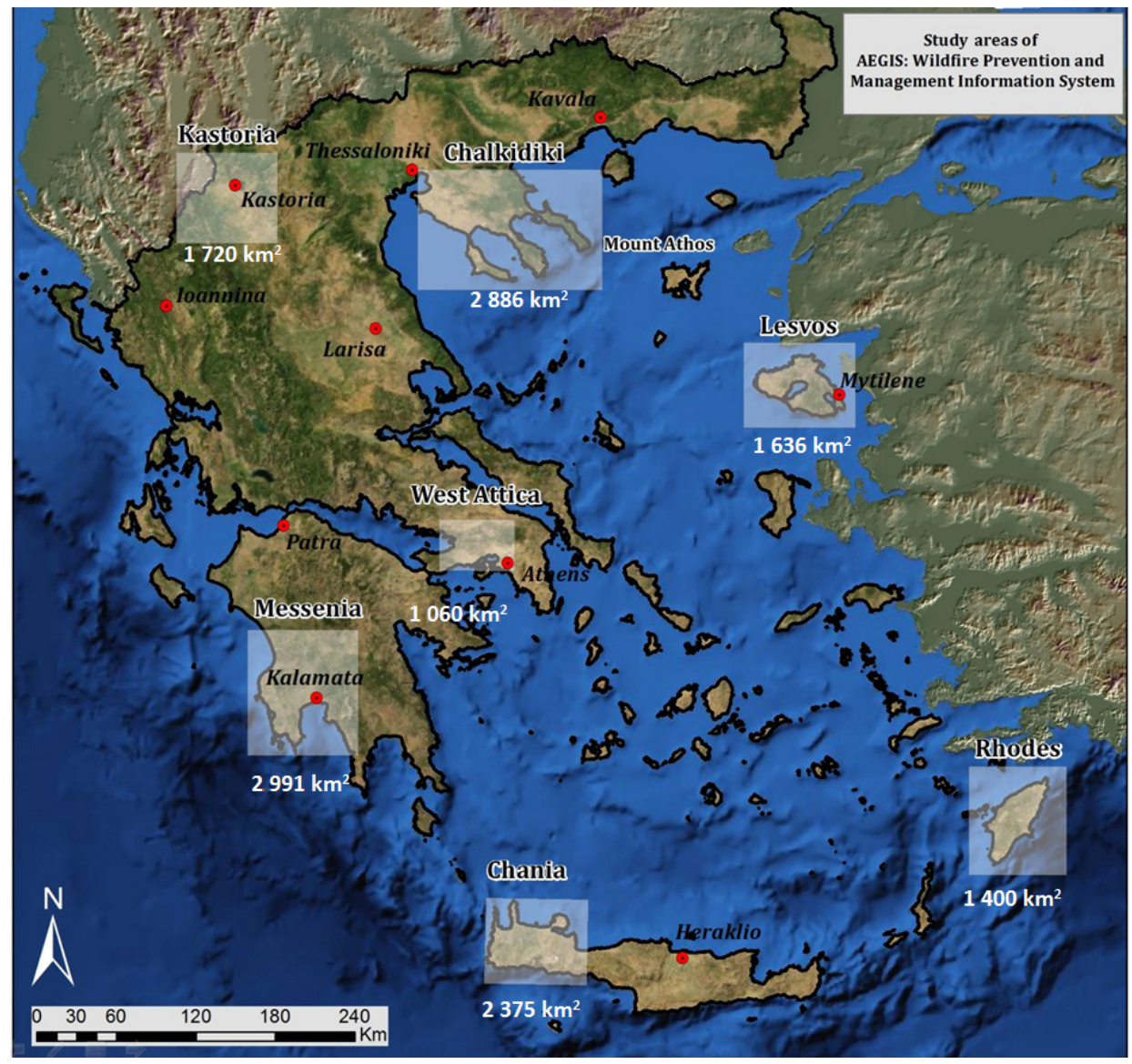

Figure 1. The seven study areas used to test AEGIS in Greece.

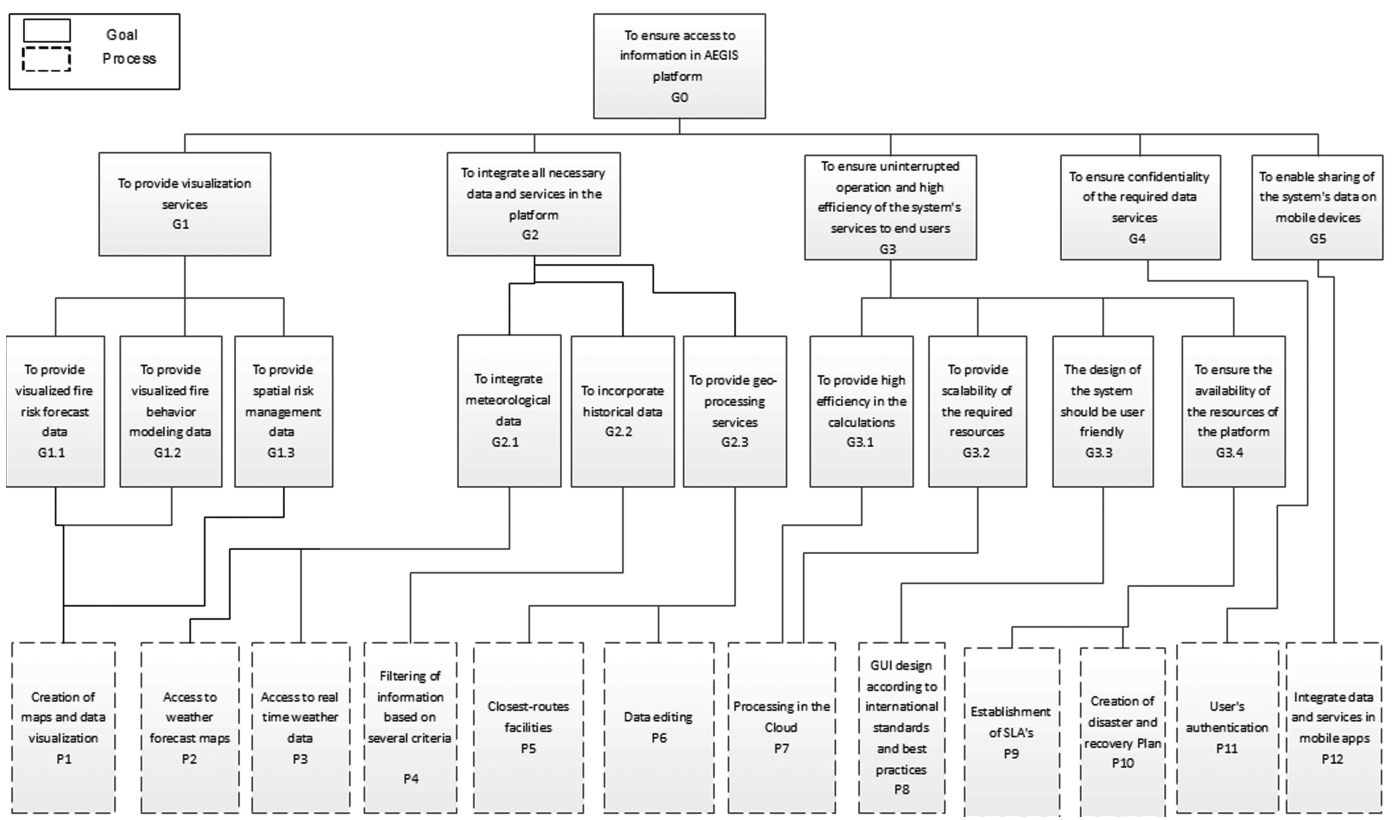

Figure 2. Goal-process diagram for development of the AEGIS platform. 
Table 1. Description of study areas used to test implementation of the AEGIS platform.

\begin{tabular}{|c|c|c|c|c|}
\hline Study area & Total area $\left(\mathrm{km}^{2}\right)$ & Permanent residents & $\begin{array}{l}\text { Population density } \\
\text { (persons } \mathrm{km}^{-2} \text { ) }\end{array}$ & Socioeconomic/environmental factors \\
\hline Kastoria & 1720 & 50000 & 29 & $\begin{array}{l}\text { Climate change has led to increased fire activity, } \\
\text { even in high-altitude mountainous areas (such } \\
\text { as Gramos), where fire has always been a low- } \\
\text { frequency natural disaster. }\end{array}$ \\
\hline Chalkidiki & 2886 & 106000 & 37 & $\begin{array}{l}\text { The region is heavily wooded with pine, oak } \\
\text { and beech forests around olive cultivations, } \\
\text { vineyards and fertile farmlands inland. There } \\
\text { is also high pressure on the landscape from } \\
\text { tourism and mining. }\end{array}$ \\
\hline Lesvos & 1636 & 86000 & 53 & $\begin{array}{l}\text { The island encompasses high fire-prone and } \\
\text { fire-risk ecosystems of Greece. Pine forests and } \\
\text { olive groves dominate almost half of the is- } \\
\text { land's area, making it one of the most tree- } \\
\text { covered islands of Greece. }\end{array}$ \\
\hline West Attica & 1060 & 161000 & 152 & $\begin{array}{l}\text { The area is affected by large wildfires and is un- } \\
\text { der continuous urban pressure, industrialization } \\
\text { and farming/livestock economic activities. }\end{array}$ \\
\hline Messenia & 2991 & 177000 & 59 & $\begin{array}{l}\text { During the summer of } 2007 \text {, devastating forest } \\
\text { fires affected a large portion of Peloponnesus, } \\
\text { including Messenia which is a high-hazard area } \\
\text { diachronically. }\end{array}$ \\
\hline Rhodes & 1400 & 116000 & 83 & $\begin{array}{l}\text { There are intense human pressures on the is- } \\
\text { land's ecosystems due to a developed tourism } \\
\text { infrastructure and from urban expansion into } \\
\text { the wildland-urban interface to cover housing } \\
\text { and recreational needs. }\end{array}$ \\
\hline Chania & 2375 & 157000 & 66 & $\begin{array}{l}\text { The ever-increasing tourist and human pressure } \\
\text { on the area has increased its vulnerability and } \\
\text { recent wildfire events have caused devastating } \\
\text { outcomes on biodiversity, social values and eco- } \\
\text { nomic concerns. }\end{array}$ \\
\hline
\end{tabular}

vided by geographical ArcGIS Server. The mobile application AEGIS App (Athanasis et al., 2015b) was implemented by utilizing ArcGIS Runtime SDK for NET API.

To utilize the available tools and services of AEGIS, users must provide credentials that are stored in a DBMS based on Microsoft SQL Server. The web server hosts the Silverlight application and the weather data management system that is responsible for automatic retrieval and management of weather forecast data and real-time weather data from several RAWS across the study areas.

The software components of ESRI ArcCatalog and ArcMap are used for the creation and management of all necessary spatial data and maps. Data are uploaded into spatial databases and published as GIS services through ArcGIS Server.

On-demand simulations of individual fires and fire hazard modeling are conducted inside an on-premises Datacenter (i.e., Aegean University Campus), while seasonal burn probability outputs are initially calculated in Virtual Machines
(VMs) in the Cloud infrastructure of Microsoft Azure and then finalized in the on-premises Datacenter. For the creation of burn probability maps, VMs in the Microsoft Azure infrastructure are allocated on specific time frames (i.e., once per month). After execution in the Cloud's and/or on-premises VMs, output results are handled by the ArcGIS Server that enables the visualization of the results from the GUI of AEGIS.

\subsection{Field Inventories, data collection and geographic databases}

One of the main objectives of AEGIS was the collection of spatial and non-spatial data to develop and organize a comprehensive geographic database for each study area to support various AEGIS functionalities. Data were collected from various agencies from all study areas, including road networks, vegetation types, fuel models, water sources, topographic data, firefighting related data, infrastructure, urban areas, forest management data, historical weather data, 
Table 2. Proposed services, goals and corresponding processes in the AEGIS platform.

\begin{tabular}{|c|c|c|}
\hline Service & Goal (G) & Process $(\mathrm{P})$ \\
\hline Visualization of fire risk maps & G1.1 & P1, P7 \\
\hline Visualization of burn probability maps & G1.2 & P2, P3, P7 \\
\hline Visualization of real time weather data & G2.1 & P3 \\
\hline Visualization of forecast weather data & G2.1 & $\mathrm{P} 2, \mathrm{P} 7$ \\
\hline \multicolumn{3}{|l|}{$\begin{array}{l}\text { Access to fire management data: i.e., } \\
\text { - base maps/satellite maps }\end{array}$} \\
\hline - water sources & G1.3 & P1 \\
\hline \multicolumn{3}{|l|}{ - evacuation sites } \\
\hline \multicolumn{3}{|l|}{ - cover types } \\
\hline \multicolumn{3}{|l|}{ - high risk areas } \\
\hline Exploitation of Google Earth (KML) data & G1.3 & P6 \\
\hline Online map creation & G2.3 & \\
\hline Map printing & G2.3 & \\
\hline Access to historical fire risk data & G2.2 & P4 \\
\hline Access to historical weather data & G2.2 & \\
\hline Access to historical burn probability maps & $\mathrm{G} 2.2$ & \\
\hline Routing & G2.3 & P5, P11 \\
\hline Finding the closest routes to water sources & G2.3 & P5, P11 \\
\hline Calculate drive times from a specific location & G2.3 & P5, P11 \\
\hline Location tracking of fire vehicles on duty & G2.3 & P6, P11 \\
\hline Visualization of new fire spots & $\mathrm{G} 2.3$ & P6, P11 \\
\hline Access to web cameras & G2.3 & P6, P11 \\
\hline Access to the provided information through mobile apps & G5 & P12 \\
\hline Fire behavior simulation & G1.2, G1.3, G2.1, G2.2 & P1, P2, P3, P11 \\
\hline
\end{tabular}

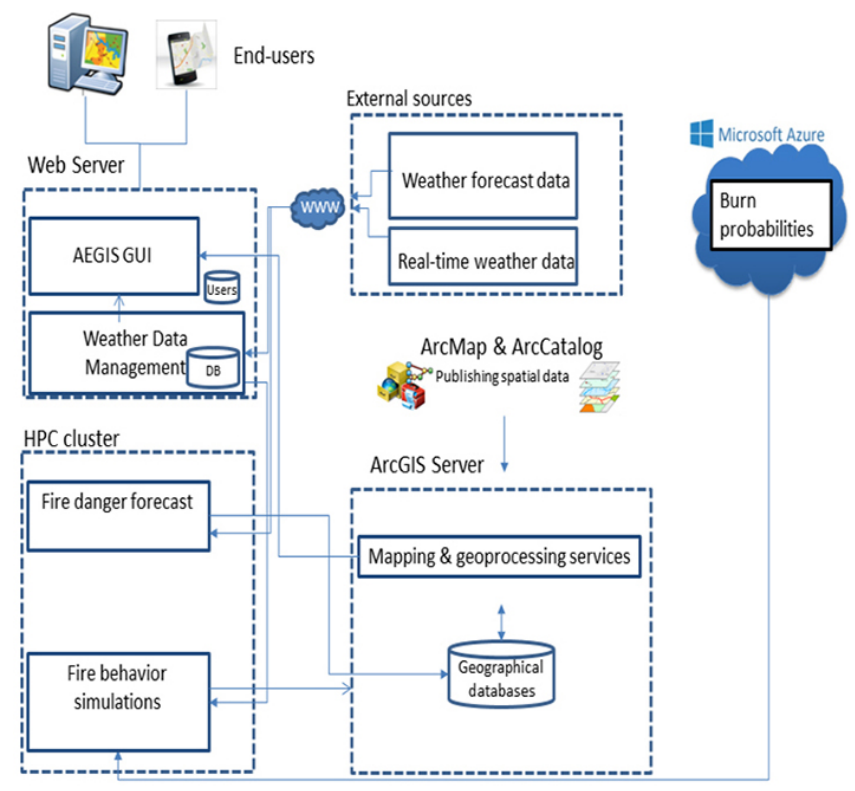

Figure 3. Architectural components of the AEGIS platform showing the linkages among data and computing resources. etc. Retrieved data were edited, updated or recreated, supplemented by metadata compliant with the INSPIRE Directive $^{6}$. For each geographic database, conceptually similar data were organized in 11 distinct groups (i.e., geophysical, forestry/vegetation, fire history, administration, high-risk areas, networks and infrastructure, water sources, high protection sites, annotations, firefighting infrastructure, and raster data and maps) using ArcGIS.

Weather forecast maps are prepared daily and stored in geographic databases using the SKIRON limited area weather forecasting system, based on the Eta/NCEP model (Janjić, 1994; Kallos et al., 1997). SKIRON covers the entire Greek territory with a high horizontal resolution of $5 \mathrm{~km}$ and a forecasting period of 5 days $(120 \mathrm{~h})$. Weather forecast maps of wind speed and direction, humidity, air temperature, cloud cover and precipitation are provided every $3 \mathrm{~h}$ for the next $72 \mathrm{~h}$.

Detailed land use and cover type maps were created based on innovative image processing methodologies with highresolution multispectral RapidEye satellite images $(5 \mathrm{~m} \mathrm{spa-}$ tial resolution). Field inventories were organized to collect data on vegetation type, stand height, canopy base height and fuel model. The collected information was used in conjunction with auxiliary data, such as vegetation spatial data from

\footnotetext{
${ }^{6}$ http://www.ec-gis.org/inspire
} 
CORINE 2000 vegetation classification system (EEA, 2002) and other forest management data, during the vegetation map creation process. To account for seasonal effects on vegetation, two image mosaics of each study area were used for two time periods of the same reference year. Satellite image processing was conducted in three stages: preprocessing, dividing each study area into homogeneous physiographic zones; classification, with a fuzzy set technique and application of a segmentation algorithm; and post-classification, applying convolution filters for image smoothing. Finally, corrections were applied on the results (vector files) by visual interpretation, digitization and cover type characterization over aerial orthophotos.

Standard fuel models were used for four out of the seven study areas, while the remaining three study areas were assigned a set of custom fuel models to describe the different fuel conditions of Pinus brutia, a common pine species of eastern Greece. Four fuel models were used to describe these pine forests, as described by Palaiologou et al. (2013). Tests on a number of wildfire events occurred in this vegetation type revealed that standard fuel models presented overestimations of both final fire size and wildfire progression through time (Kalabokidis et al., 2013c).

\subsection{Fire behavior modeling}

AEGIS utilizes the MTT algorithm for fire behavior predictions and fire hazard estimation, in conjunction with FlamMap5 modeling capabilities (Finney, 2006). The MTT fire spread algorithm and associated crown fire models as implemented in the FlamMap code libraries is by far the most widely used and tested fire simulation in the world. MTT has been applied in strategic and tactical fire management planning in the US (Ager et al., 2011) and integrated into FARSITE (Finney, 1998), FlamMap5 (Finney, 2006), FSim (Finney et al., 2011b), FSPro (Noonan-Wright et al., 2011), Randig (Ager et al., 2007, 2014) and other models in the research domain. Application and testing also includes fire systems outside of the US, including France, Spain, Italy and Portugal (Alcasena et al., 2015; Salis et al., 2013, 2015) where the MTT algorithm encapsulated in Randig and FConstMTT (command line-based executable) was used to model fire exposure to highly valued resources, and to model the effect of fuel breaks on wildfire spread.

Under constant fire weather conditions, the MTT algorithm searches for the fastest path of fire spread along straight-line transects connected by nodes (cell corners) and exposes the effects of topography and the arrangement of fuels on fire growth (Finney, 2006). The MTT algorithm can be used to compute potential short-term fire behavior characteristics (rate of spread, fireline intensity, time of arrival, flow paths, etc.) for a single fire or simulate many fires to generate conditional burn probabilities and flame lengths using Monte Carlo stochastic simulations, where fire weather and fuel moisture information varies among the simulated fires
(Ager et al., 2007; Finney et al., 2011b). Burn probability is an estimate of the likelihood of a pixel burning given a single random ignition under burn conditions in the simulation. Burn probability modeling represents a major advancement in wildfire behavior modeling and risk assessment compared to previous methods, such as those where fire likelihood was quantified with relatively few predetermined ignition locations (i.e., fewer than 10). As a result, the product of this process is a burn probability map that reveals areas that are more likely to burn. The FlamMap5 library generates a number of additional outputs that we included in AEGIS including flame length, rate of spread, fireline intensity, heat per unit area, crown fire activity and midflame wind speed.

For individual fire simulations, MTT is implemented within AEGIS in a transparent web-based GUI. When a fire simulation is triggered, a command line execution of MTT starts the simulation inside the HPC cluster. If multiple users begin their simulations simultaneously, each simulation is assigned to one of the available HPC nodes and execution takes place in parallel. Upon the completion of execution, several output files are generated either in GRID ASCII format (arrival time, fireline intensity, ignition point and rate of spread) or vector files with information for regular and major flow paths (Finney, 2006). After output files are created, several ArcGIS Server geo-processing services are executed to convert GRID ASCII outputs to vector format and store them in feature classes inside a geographical database. Finally, ArcGIS Server mapping services retrieves the appropriate information from feature classes using a filtering process to select simulation outputs and display map outputs in the AEGIS platform.

In Fig. 4, the information flow for the MTT execution in AEGIS is shown. End users trigger a new simulation (step 1), and the first available machine retrieves input parameters and starts a new process of MTT execution (step 2). Outputs are stored in a shared repository (step 3) where a geo-processing service retrieves them (step 4), performs necessary data transformations, stores them in a geo-database (step 5) and, finally, notifies users that the execution is finished. Visualization of results is achieved by utilizing mapping services directly over the AEGIS platform (step 6).

Seasonal burn probability and flame length maps are automatically generated periodically (e.g., once per month), by simulating thousands of possible wildfire ignitions across each study area with the Cloud Computing infrastructure of Microsoft Azure. This process is intended to provide regional probabilistic risk-based forecasts of potential fire occurrence and behavior (Kalabokidis et al., 2013b, c, 2014a). During an execution, the VMs in the Microsoft Azure infrastructure are allocated and FConstMTT is executed simultaneously on each VM.

The phases for conducting seasonal burn probability and flame length maps on Microsoft Azure cloud infrastructure are as follows: 


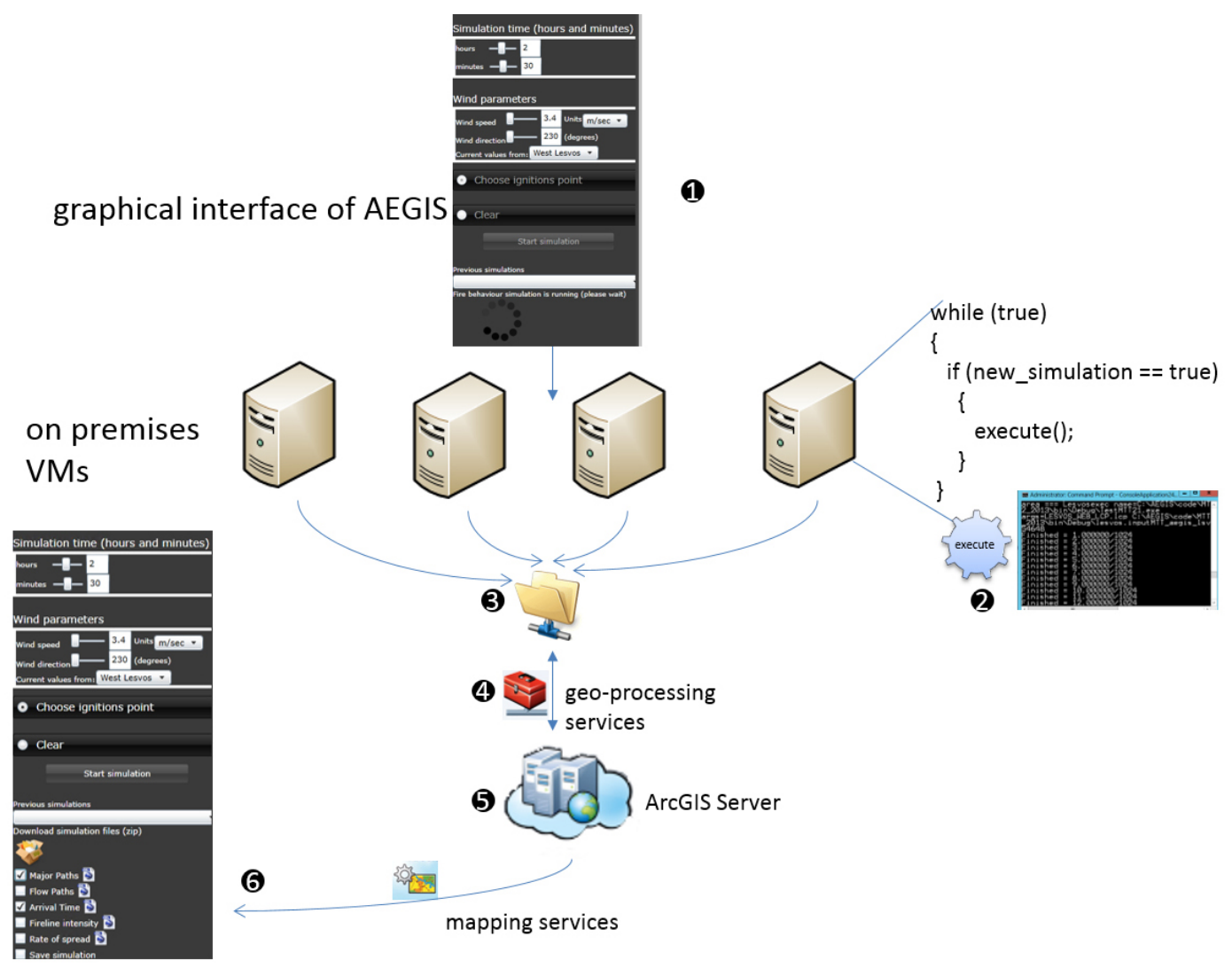

Figure 4. Information flow for on-demand MTT simulations of individual wildfires in AEGIS.

- Initialization: a deployment is uploaded in the Microsoft Azure cloud infrastructure that runs FConstMTT command line-based executable.

- Execution: parallel execution of the FConstMTT executable is conducted by dividing the overall number of ignition points equally among the available VMs. This partitioning of the ignitions significantly reduces execution time.

- Merging: output results are combined into a new ASCII text file to calculate burn probabilities and flame length categories (i.e., 20 categories) for all ignitions.

- Extraction: burn probabilities and every flame length category are extracted from the merged output.

- Visualization: the extracted outputs are loaded in a geodatabase and visualized through the AEGIS platform. Furthermore, outputs are available for download from end-users to perform meta-analysis (e.g., with ArcFuels).

In Fig. 5, the information flow for the creation of a seasonal burn probability map in AEGIS is presented. The deployment is uploaded from one of the on-premises machines to the Cloud (step 1). Execution starts concurrently at available VMs (step 2). Partial output results are created and a merged file is generated that stores all values for all output categories (step 3). From the merged file, all output categories are extracted in separated output files (step 4), converted to raster files (step 5) and stored in a geo-database (step 6) for visualization purposes (step 7).

\subsection{Fire hazard system}

A prototype spatial fire hazard estimation system was developed and incorporated into AEGIS that uses both ignition probability and expected burn area, thus providing an integrated fire hazard metric (e.g., Miller and Ager, 2013; Scott et al., 2013). Initially, ANN were used for the mathematical modeling of conditional probability of ignition (CPI), based on independent variables (i.e., latitude, longitude, altitude, month, day of week, distance from urban areas, distance from power lines, distance from main and secondary roads, distance from landfills, distance from agricultural areas), in conjunction with spatial weather forecasts from SKIRON that depict wind speed, rain, relative humidity and temperature. Historical ignitions were used to derive the spatial patterns of wildfire occurrence of each study area, constituting the base of the ANN training procedures. 


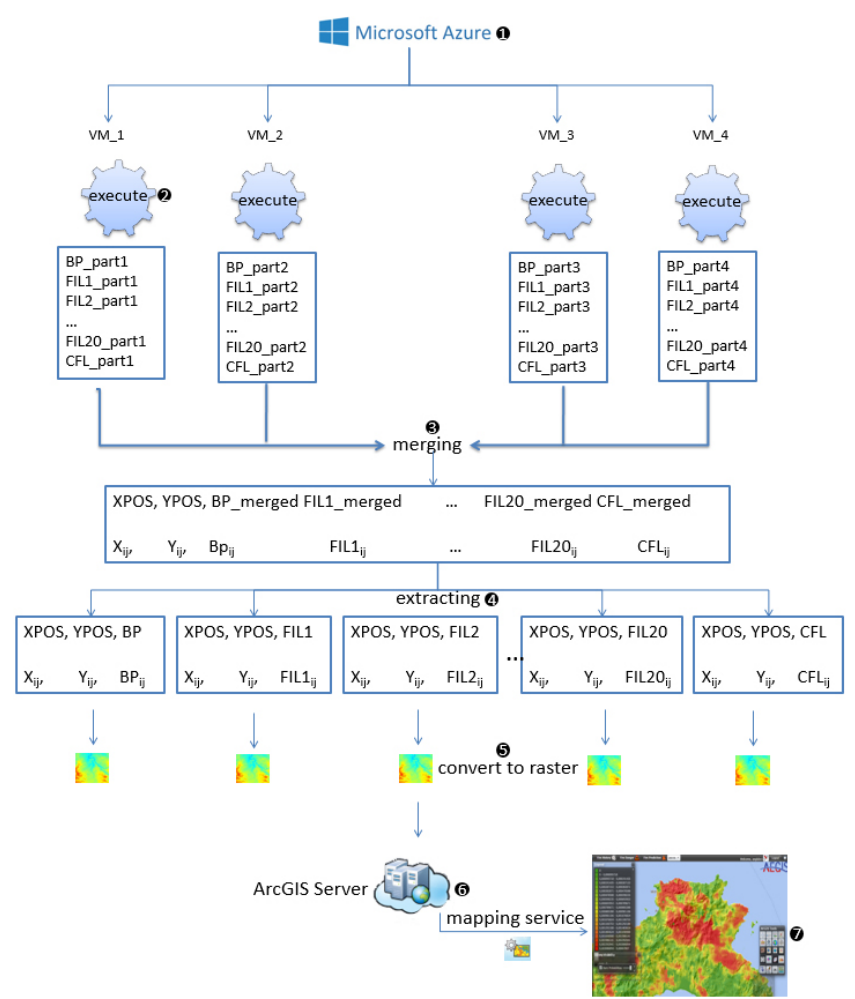

Figure 5. Information flow for the estimation of burn probability maps in AEGIS.

We experimented with multiple methodologies including the Back Propagation Neural (BPN) Networks (Rumelhart et al., 1986), the Kohonen Networks (Self Organizing Maps) (Kohonen, 1982), and two types of Radial Basis Function (RBF) Networks (Tsekouras et al., 2015). The backpropagation method proved to perform better compared to the other two. As a result, this method was selected and applied for operational use. Development of the final algorithm was based on trial and error techniques. Three different activation functions were tested for transferring the signal between input and hidden nodes; i.e., logistic sigmoid, hyperbolic tangent sigmoid and linear functions. The input parameters were either unprocessed or normalized. Finally, the training process was controlled by the early stopping method, where the number of validation samples and the maximum number of training epochs were monitored (Prechelt, 1998). For each possible combination of the above parameters, a back-propagation neural network was developed with one hidden layer of five to 20 processing nodes. Eighty percent of the sample was used for training, while the remainder was utilized during the validation stage. The selection of these samples was randomized during the initialization stage. Each network was trained for 10 initializations; therefore, 1008 networks were developed for each study area. Based on the above results, the best-performing networks of root mean square error (RMSE) of the validation data set were saved for each area and integrated into the graphical interface of AEGIS to be used for the computation and cartographic representation of wildfire ignition risk. By using FlamMap, the predicted burned area (PBA) is estimated using the elliptical dimensions output grid themes that give the $a, b$ and $c$ dimensions (expressed by rate of spread on meters per minute) for a simple ellipse (Finney, 2001), to derive the burned area per pixel for a time period of $3 \mathrm{~h}$. The spatial data of the SKIRON model for wind speed and direction are provided as FlamMap input, while relative humidity and air temperature values are used to estimate fuel moisture values.

The $10 \mathrm{~h}$ fuel moisture content $(\mathrm{m})$ is computed based on relative humidity $(H)$ and air temperature $(T)$ by using the following algorithm (Viney, 1991):

$$
\begin{aligned}
m & =5.658+0.0465 \times H+3.151 \times 10^{-4} \times H^{3} \\
& \times T^{-1}-0.1854 \times T^{0.77} .
\end{aligned}
$$

The 1 and the $100 \mathrm{~h}$ fuel moisture values are calculated by subtracting and adding $1 \%$ to the $10 \mathrm{~h}$ fuel moisture, respectively, while the values of live herbaceous and live woody moisture are predefined based on the actual date of each fire event, linked to the standard fuel moisture scenarios of the BehavePlus software according to Table 3. Finally, CPI is combined with PBA in the matrix of Table 4 to derive the resulting fire hazard index in five categories from Low to Extreme levels.

\subsection{Access to data and services}

All services and data provided by AEGIS are accessible through a web-based interface eliminating the need to install specific desktop software. This minimizes deployment time and eliminates client costs for software, thus enabling any authorized user to immediately access the GUI from anywhere in the world over the Internet. Users have the ability to perform GIS tasks and utilize resulting products within the GUI (Fig. 6). The mapping schemes of Bing Maps and Open Street Maps provide high-resolution satellite images and detailed thematic maps with annotations and road network information, used as background mapping layers of AEGIS. Land use/land cover types can also be selected and displayed, along with annotations, study area boundaries and urban areas. Apart from background layer selection, users have access to information to support forest fire suppression efforts. This information includes the road network, water sources, fire watch outlooks, monuments, helipads, gas stations, landfills, evacuation sites, and firefighting vehicle patrol sites. Several tools and services such as live camera image streams, geo-processing tools, and elevation profiling of any area of interest are integrated. Spatial queries regarding the drive time distances from a site and the locations of closest water tanks, fire hydrants and pumping stations are also provided, as well as the analysis of the shortest routes among locations on the map based on the Bing Maps routing scheme. 


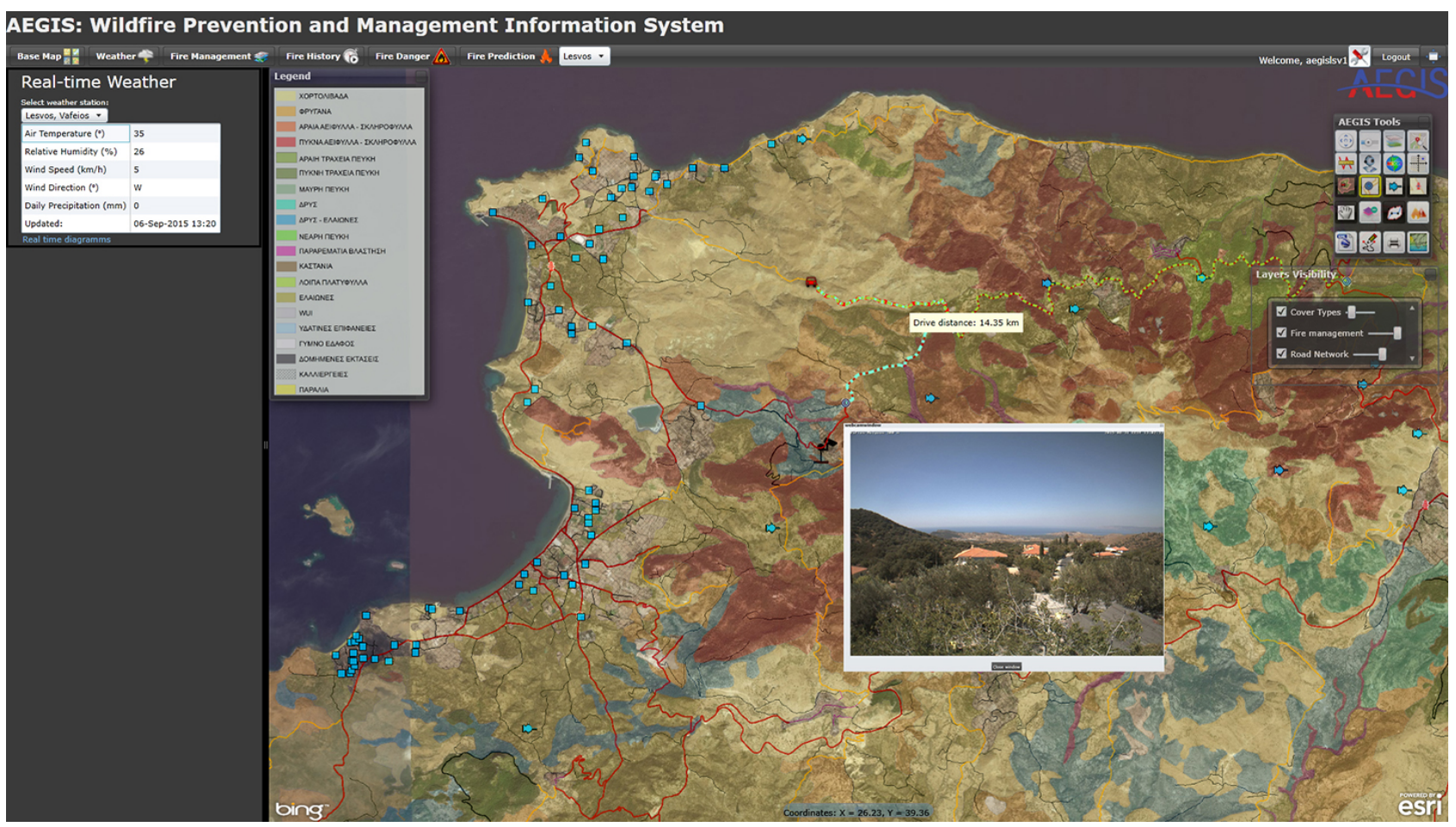

Figure 6. Optical camera surveillance combined with visualization of the road network, the pumping stations, the cover types and real-time weather records from the closest RAWS within the AEGIS graphical interface.

Table 3. Live herbaceous and live woody moisture values $(\%)$ used for wildfire simulations.

\begin{tabular}{lcccccccccc}
\hline & Jan-April & May & June & July (1-14) & July (15-31) & Aug & Sept (1-14) & Sept (15-30) & Oct & Nov-Dec \\
\hline Live herbaceous & 120 & 90 & 60 & 50 & 40 & 30 & 40 & 50 & 60 & 120 \\
Live woody & 150 & 120 & 90 & 80 & 70 & 60 & 70 & 80 & 90 & 90 \\
\hline
\end{tabular}

Furthermore, SKIRON weather forecast maps of wind speed and direction, air temperature, cloud cover and precipitation can also be visualized by selecting the date, time and variable of interest. In addition, real-time weather data and weather records from RAWS are provided for any desired time period.

End-users are able to conduct fire behavior simulations or access and view previously stored simulations. If the user decides to conduct a new simulation, the ignition point (by clicking on the map or by providing coordinates) and the duration time (hours and minutes) of the simulation must be specified. The duration time cannot exceed $6 \mathrm{~h}$, since MTT provides higher simulation accuracy for short-term time periods. Real-time wind parameters (speed and direction) are retrieved from RAWS (either the closest to the ignition point or one from the available) or can be user-defined to conduct "what if" scenario simulations with an additional specification of a fuel moisture scenario. After providing required inputs, users can trigger the "Start Simulation" button. When a fire simulation is initiated, MTT is executed and necessary input parameters are read from a configuration file generated at runtime. Through the GUI, information is steadily provided regarding the simulation status for as long as execution is in progress (Fig. 7a). At the end of the simulation, all outputs can be directly visualized by enabling a checkbox next to each mapped attribute (Fig. 7b). Individual outputs can also be downloaded as either kml layers or alternatively, in their raw format (GRID ASCII or shapefiles) as a zip file.

Data and services of AEGIS are also accessible through the mobile application AEGIS App (Fig. 8a-c). The AEGIS App provides access to key services of fire management, especially to the operational end-users at the front line. In case of a fire emergency, end-users in the field can utilize the mobile app, and the location of the fire is directly incorporated in the graphical interface of the web platform of AEGIS. To the best of our knowledge, this is the first wildfire management application for native Windows Phone devices. Upon opening the AEGIS App, the current end-user location is tracked (received from the GPS sensor of the device) and visualized as a fire vehicle symbol on top of the background 
Table 4. Union matrix of probability of ignition and burned area to derive fire hazard ratings.

\begin{tabular}{|c|c|c|c|c|c|c|}
\hline & & \multicolumn{5}{|c|}{ Predicted burned area (PBA) } \\
\hline & & $<1$ ha & $1-10$ ha & $10-100$ ha & $100-1000$ ha & $>1000$ ha \\
\hline \multirow{5}{*}{$\begin{array}{l}\text { Conditional probability } \\
\text { of ignition }(\mathrm{CPI})\end{array}$} & $0-20 \%$ & Low & Low & Moderate & Moderate & High \\
\hline & $20-40 \%$ & Low & Moderate & Moderate & High & High \\
\hline & $40-60 \%$ & Moderate & Moderate & High & High & Very high \\
\hline & $60-80 \%$ & Moderate & High & High & Very high & Very high \\
\hline & $80-100 \%$ & High & High & Very high & Very high & Extreme \\
\hline
\end{tabular}

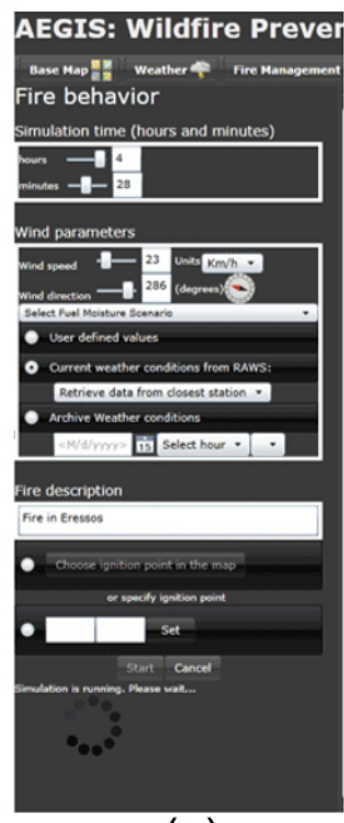

(a)

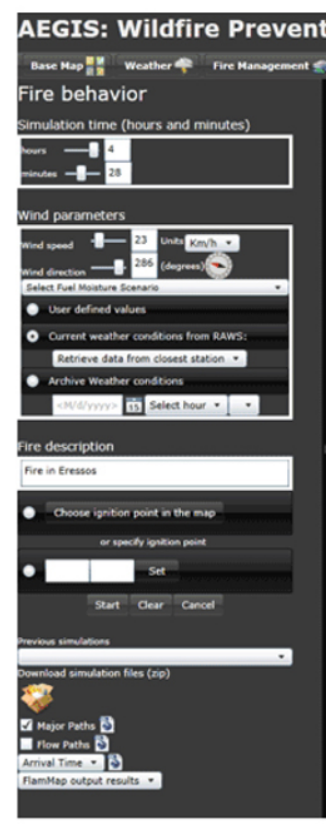

tion and Management Information System

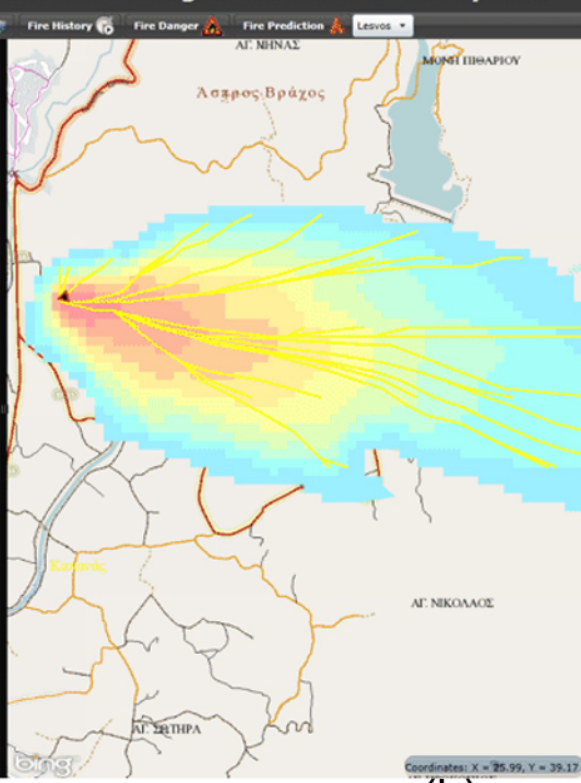

(b)

Figure 7. Visualization of a single fire simulation within the AEGIS graphical interface.

mapping schemes (Bing Maps or Open Street Maps). Below the map, options and icons exist that provide access to different functionalities. Several tasks can be accomplished from the AEGIS App, such as routing, spatial search for closest facilities and firefighting support infrastructures, access to weather data and visualization of fire management data (water sources, gas refill stations, evacuation sites, etc.). An innovative feature of AEGIS App is the support of these tasks by a new digital assistant for artificial intelligence named Cortana (developed by Microsoft for Windows Phone devices), that allows information utilization through voice commands. The voice commands are executed in an automatic and transparent way and the result is visualized on the screen of the mobile phone without any further user intervention. Especially during a fire emergency, this feature absolves end-users from text typing and filling of forms, which can be a very timeconsuming task.

\section{Results}

Results of wildfire propagation and fire hazard for six of the larger fire events that actually started and burned in our study areas during the summer of 2015 are presented in Figs. 9 and 10 . The propagation simulations were conducted at the beginning of each wildfire through the AEGIS platform by designated trained civil protection officers. West Attica's incident burned 50 ha (Fig. 9a); Chalkidiki's wildfire burned approximately 150 ha (Fig. 9b), while three wildfire outbreaks on Rhodes resulted in a total of 450 ha of forest lands burned (Fig. 9c-e). On Lesvos, a wildfire burned approximately 550 ha (Fig. 9f). Suppression efforts and major fire runs occurred for up to $3-10 \mathrm{~h}$ after ignition in these wildfire events. Three of these wildfires started in moderate-hazard areas (Fig. 10a-c) and three wildfires started in very highhazard areas (Fig. 10d-f) in our spatial fire hazard system, as the summer fire season progressed through June to August 2015. 

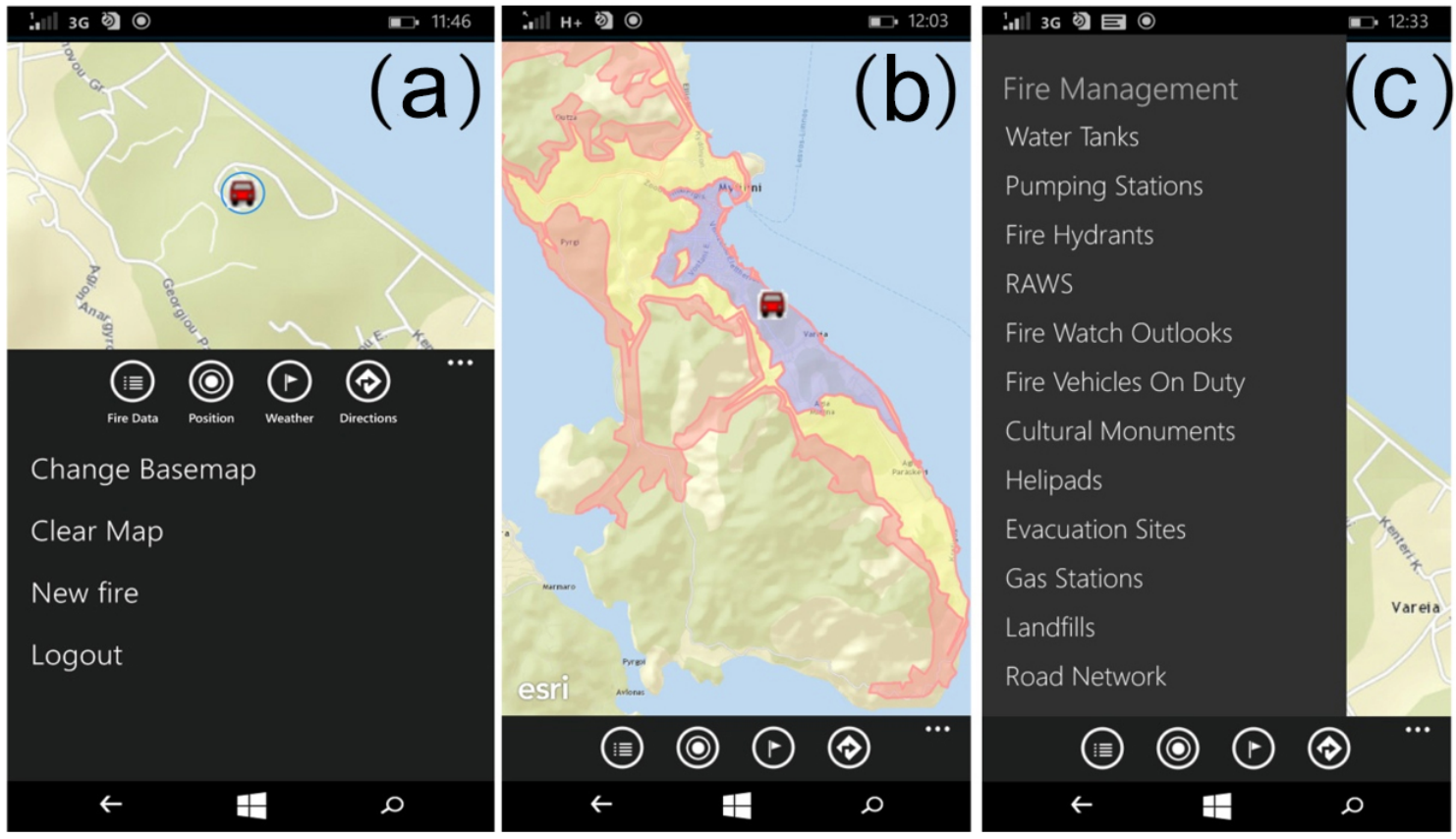

Figure 8. (a) Basic screen of AEGIS App; (b) calculation of the areas that the user can access by driving a regular firefighting truck in 3,5 and $10 \mathrm{~min}$; and (c) accessing fire management data through the AEGIS App.

Wildfire perimeters were initially derived from EFFIS databases ${ }^{7}$ that rely on remote sensing techniques with lowresolution MODIS ${ }^{8}$ satellite data $(250 \mathrm{~m}$ ground spatial resolution). Civil protection agencies were instructed to conduct simulations through the AEGIS platform upon the start of a new fire, by defining 3 hours of duration (i.e., the early stage of the suppression efforts), and using weather data from the nearest RAWS at the time of ignition. Fine tuning could be made in case of feedback from the field crews, suggesting that wind speed and direction values should be altered. Ignition points were also set by approximation, based on information coming from the field (no GPS signal is taken in Greece at the beginning of each event). Furthermore, the propagation results did not consider any firefighting actions and activities taking place during the evolution of the event, thus they represented the uncontained fire growth over a period of $3 \mathrm{~h}$.

Results revealed that simulations captured the general shape of fires, while major travel paths were accurate as to where the fastest propagation actually occurred. All simulations over-predicted the actual fire area, with the exception of the Lesvos wildfire, an acceptable outcome given all the assumptions and considerations of the simulation procedure. The fire on Lesvos had the largest actual area and duration (Fig. 9f) compared to all other case fires, exceeding 500 ha of burned forest lands. A clear wind direction shift

\footnotetext{
${ }^{7}$ http://forest.jrc.ec.europa.eu/effis/about-effis/ technical-background/rapid-damage-assessment/

${ }^{8}$ http://modis.gsfc.nasa.gov/
}

from NE to $\mathrm{N}$ occurred when the fast-moving front inside a gully surpassed the mountain ridge after the first hours of burn time in the Lesvos fire; fuel models and topography also changed for a second fire run, thus explaining differences between simulated vs. actual wildfire perimeters. To adjust to these changes, we conducted a supplementary simulation for another $3 \mathrm{~h}$ and results revealed that the wildfire reached its total/actual perimeter at a comparable time to the actual event (Fig. 11). End-users may run simulations with trial and error attempts, involving multiple "what if" scenarios within AEGIS. Civil protection agencies found results helpful, promising and very informative on estimating wildfire growth, intensity and propagation speed.

Regarding our spatial fire hazard index, it was noticed that relatively moderate hazard ratings dominated the study areas early in the fire season (June 2015), while high to very high hazard ratings were more common during the latter part of the fire season (July-August 2015). As expected, wildfires occurred throughout the study areas according to the conditional probability of ignition; however, the ignitions in moderate-hazard areas (West Attica and Chalkidiki) resulted in smaller burned area (i.e., small predicted burned area) than the ignitions in higher-hazard areas (Rhodes and Lesvos).

\section{Discussion}

The need for more sophisticated approaches to wildfire management is becoming increasingly recognized by fire protection agencies worldwide. Megafires are a global phenomenon 


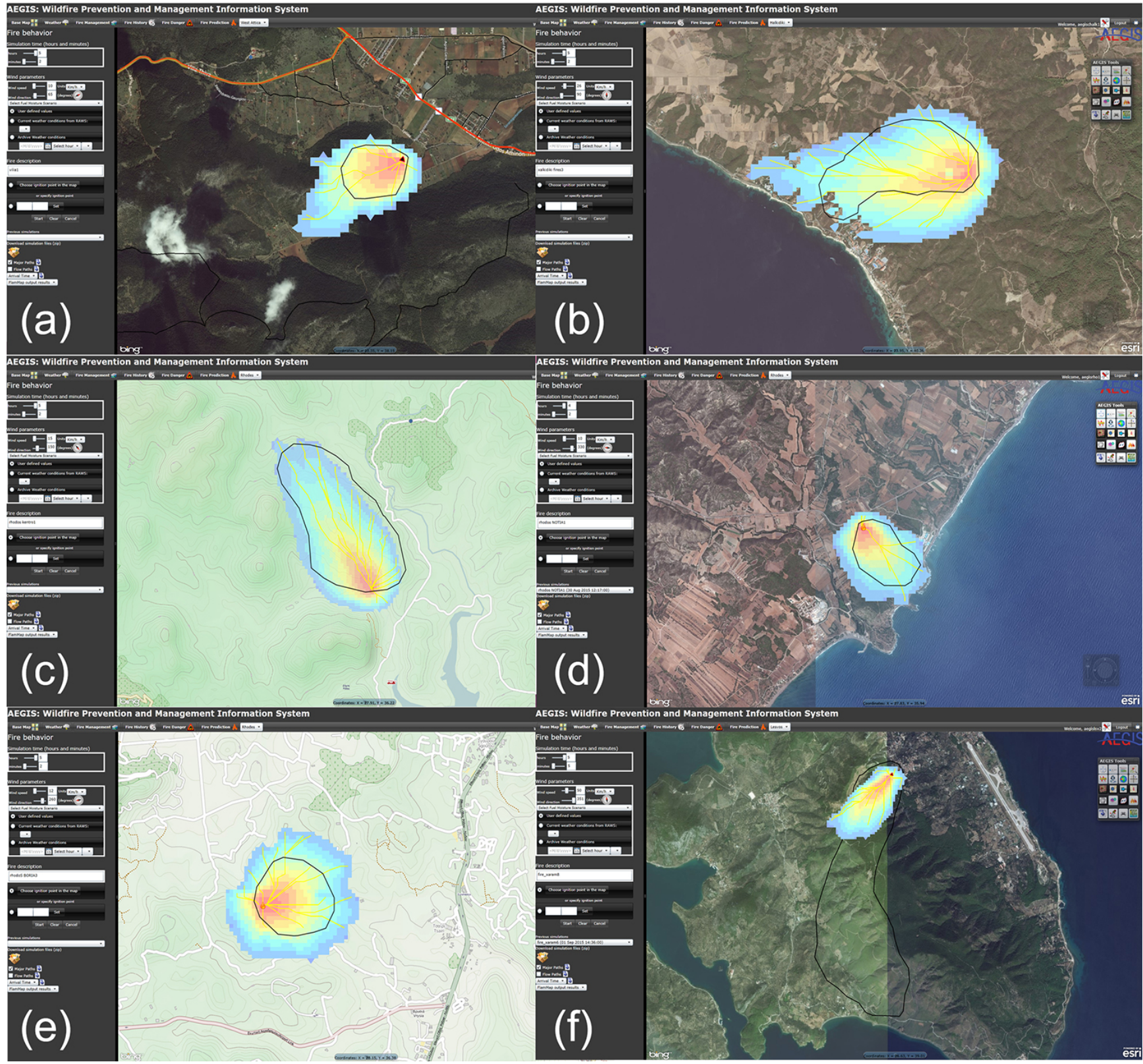

Figure 9. Simulation results of the six actual wildfires that occurred during the summer of 2015 in four of our study areas (a: West Attica, 13 June 2015, 50 ha burned; b: Chalkidiki, 16 June 2015, 150 ha burned; c: Rhodes, 23 July 2015, 323 ha burned; d: Rhodes, 31 July 2015 , 50 ha burned); e: Rhodes, 23 August 2015, 77 ha burned; and f: Lesvos, 30 August 2015, 550 ha burned) - black polygons delimit the actually burned areas, while colored areas and lines map times of arrival and major travel paths in AEGIS.

(Attiwill and Binkley, 2013) and routinely overwhelm government capacities for their control and suppression (Cruz et al., 2012; Williams, 2013). Harnessing new technology in computing capabilities, software integration, cloud services and geospatial processing offers the potential to create nextgeneration decision support tools to combat the growing incidence of catastrophic fires. Our work on an integrated decision support system for Greece resulted in the AEGIS system, an integrated approach to wildfire decision support that provides a spatial fire hazard rating, fire behavior modeling (for both single fire behavior simulations and burn probability maps), visualization of real-time and forecast weather data, access to fire management and historical fire data, and fire management tools (e.g., elevation profile, visualization of the shortest routes to the closest firefighting facilities, and real-time images of high-risk areas through web cameras). The net result is that fire intelligence and resources can be more easily shared among fire agencies, thus reducing costs 


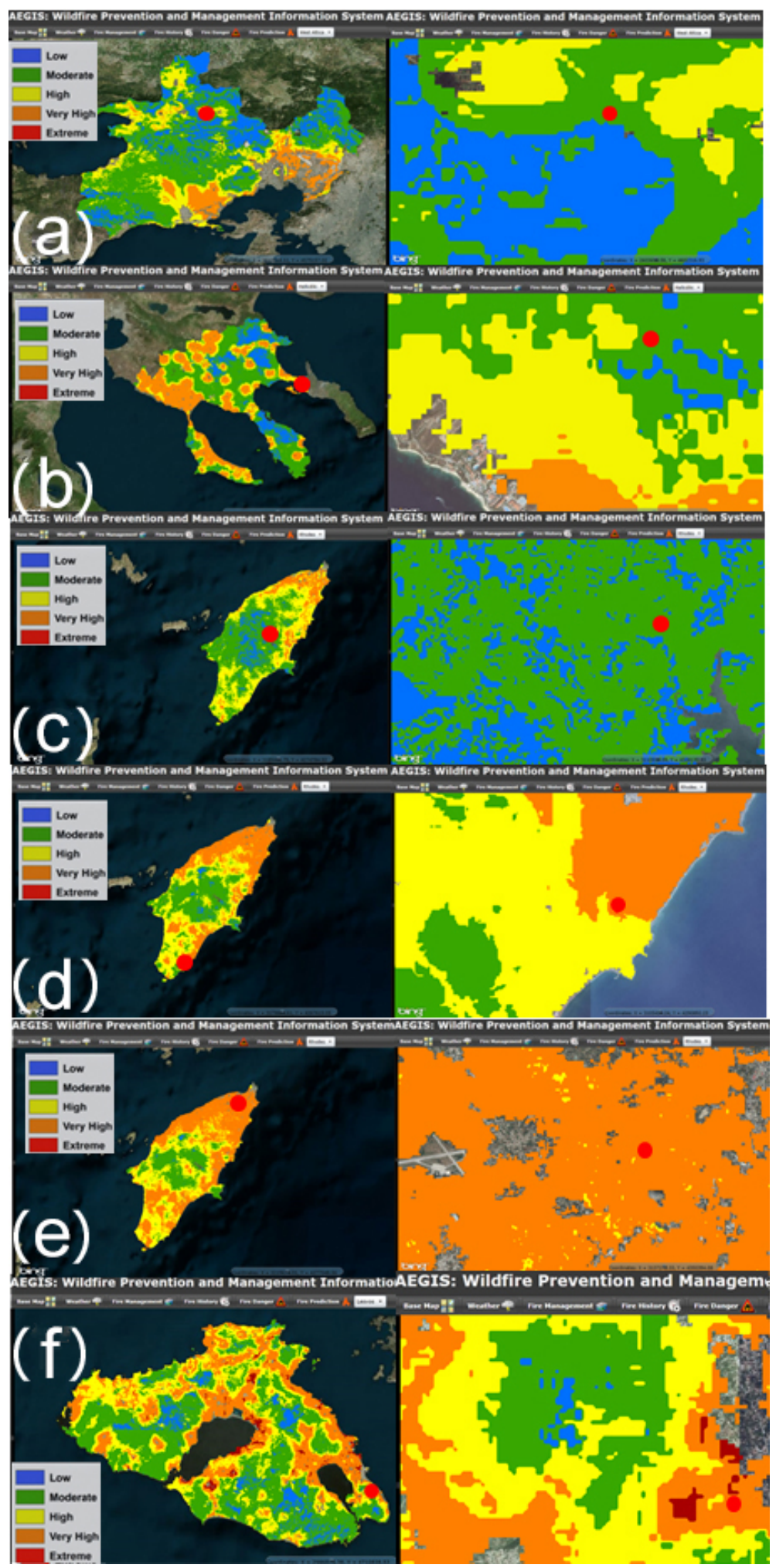

Figure 10. Spatial fire hazard results (left panels) of the six actual wildfires (right panels showing close-up of the starting points as red dots) that occurred during the summer of 2015 in four of our study areas (a: West Attica, 13 June 2015, 50 ha burned; b: Chalkidiki, 16 June 2015 , 150 ha burned; c: Rhodes, 23 July 2015, 323 ha burned; d: Rhodes, 31 July 2015, 50 ha burned); e: Rhodes, 23 August 2015,77 ha burned; and f: Lesvos, 30 August 2015, 550 ha burned). 


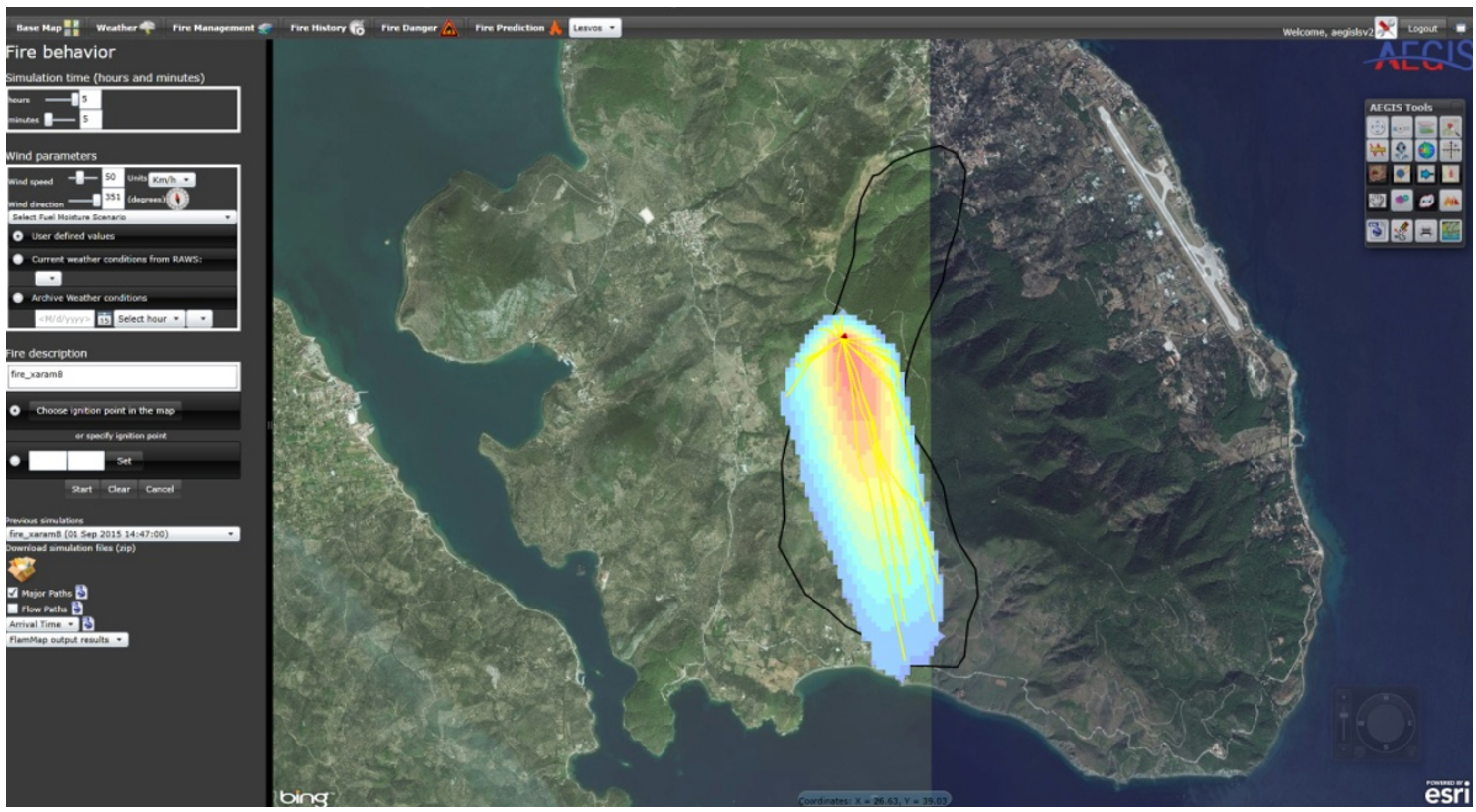

Figure 11. Second simulation run of Lesvos 2015 wildfire from the site where the first simulation ended (Fig. 9f). Black polygon delimits the actually burned area, while the colored area and lines map times of arrival and major travel paths in AEGIS.

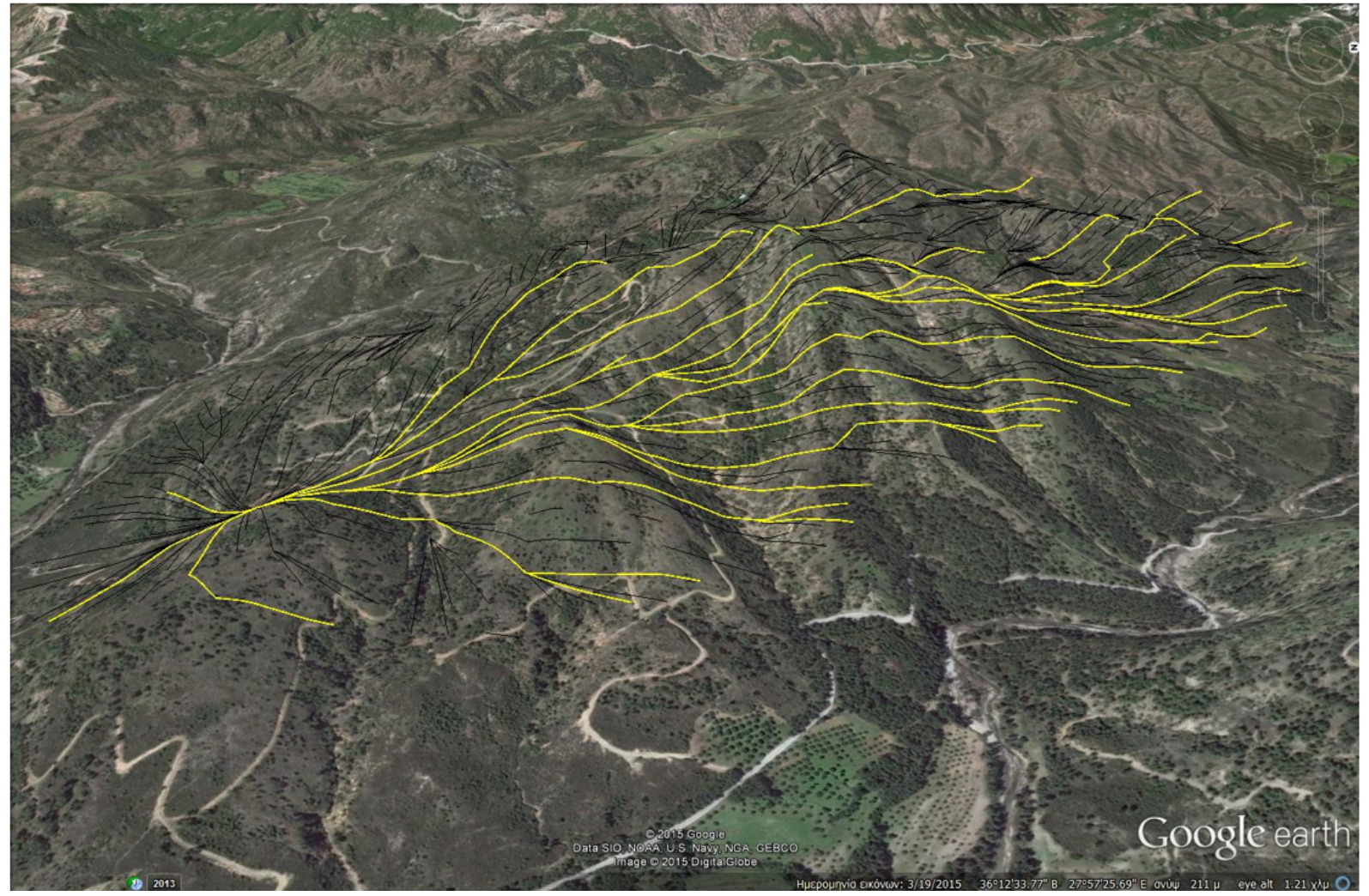

Figure 12. Visualization of travel paths from a wildfire simulation through the AEGIS platform over Google Earth. 
and enabling efficiency for suppression operations. The distributed architecture of the system eliminates the need for specialized computing and storage capabilities, further contributing to efficiencies over stand-alone and non-integrated systems. From the end-user point of view all that is needed to access the AEGIS platform is a standard computer, laptop, tablet or smartphone with internet connection. Thus, innovations in AEGIS provide advanced tools for firefighting personnel, emergency crews and other authorities to facilitate operational planning for wildfire incidents. Valuable assistance and decision support tools can be then provided to local authorities responsible for wildfire management to extract useful information as part of an operational wildfire prevention and management plan. The comparison of AEGIS with previously developed wildfire management systems (Kalabokidis et al., 2013a, 2014b) reveals that AEGIS covers the full range of forest fire management and prevention, except for damage assessment (Table 5).

The AEGIS system was intensively tested during the 2015 fire season. Local fire agencies from the seven study areas utilized the system; their personnel consulted and retrieved information from the AEGIS platform and sometimes adjusted their alertness and emergency levels, especially during days of high fire risk. Several useful conclusions and remarks were received, and several ideas were proposed for a better utilization of the platform's capabilities.

BPN networks used in AEGIS fire hazard system achieved better performance compared to other methodologies; and the BPNs were trained based on different parameters for each study area. In all but one study area (due to the smaller training data set), the RMSE of the validation data sets was less than $12.1 \%$, while the correct classification rate of ignition points was more than $80.3 \%$. Sensitivity analysis of the trained BPNs proved that the initial choice of the study areas was justified because of the different wildfire ignition patterns that were finally identified. Results showed that the distance from urban areas was a critical parameter for wildfire ignition, while air temperature seemed to have the smallest influence compared to the rest of the parameters for all the study areas.

Regarding the fire propagation/behavior scheme, the integration of the MTT algorithm enabled end-users to overcome the difficulties that arise from the lack of knowledge or the complexity in usage of fire behavior systems (e.g., BehavePlus, FARSITE, FlamMap). Interconnectivity with Google Earth, the primary GIS application of most Greek civil protection agencies, brings a new perspective on interpreting simulation results from AEGIS by using functionalities such as 3-D visualization (Fig. 12).

Our methods for calculating burn probability and generating maps using parallel processing techniques provided the necessary processing power and computational speed for operational implementation. The instant and prompt availability of processing power along with cost effectiveness, reliability and scalability of the Cloud make it an ideal computational

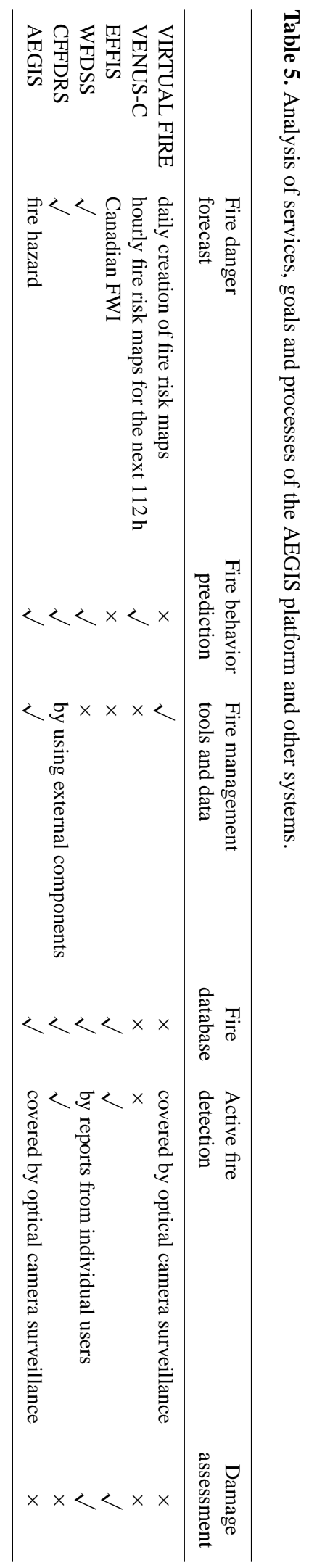

www.nat-hazards-earth-syst-sci.net/16/643/2016/ 
platform for wildfire management problems. By taking advantage of the Cloud's ability to increase/decrease the number of available VMs on demand, end-users will only consume processing resources during the actual wildfires. Ondemand fire simulations are better suited to run locally rather than in the Cloud. This is because of the significant amount of time overhead (approximately $15 \mathrm{~min}$ ) required to allocate new VMs in Microsoft Azure. On-demand fire behavior simulations need to be conducted instantly and thus, time overheads should be minimized to achieve a timely and effective response when a wildfire breaks out.

\section{Conclusion}

The AEGIS system can potentially contribute towards a more sophisticated knowledge transfer among the various entities involved in wildfire suppression activities including operation centers and firefighting units in the field. The system is designed for wide-scale deployment for the different geographical areas of Greece or regional countries with minimal effort and resources, providing the development of the required input databases and services. We demonstrated a highly scalable implementation of the system that leverages Cloud Computing and HPC resources, allowing AEGIS to be applied at the national and regional scale. Moreover the mobile application, which currently is only implemented in Windows Phone devices, will eventually be made available for Android and iPhone devices, as well. Future updates of the AEGIS will provide end-users with the ability to perform simulations from their smartphones, and visualize the results of the fire behavior directly in their mobile device. Future work will also include validation of the fire perimeters (actual vs. simulated ones produced by MTT), as well as the integration of the Fire Ranking and Effects Index (FIRE Index) for the evaluation of fire effects (Kalabokidis et al., 2014c). Further research plans include the utilization of different open source Cloud solutions (e.g., OpenStack, promoted by the OpenStack Foundation) for the calculation of spatial fire hazard and fire behavior modeling, and the utilization of opensource Web-GIS solutions (e.g., Geoserver) for the manipulation of geo-processing and mapping services.

Acknowledgements. The research project "AEGIS: Wildfire Prevention and Management Information System" (Code Number 1862) is implemented within the framework of the Action ARISTEIA of the Operational Program "Education and Lifelong Learning" (Action's Beneficiary: General Secretariat for Research and Technology), and is co-financed by the European Union (European Social Fund) and the Greek State. We also thank our entire research team for making this research project possible and Michelle Day for editorial assistance, along with reviewers for their comments.

Edited by: T. Glade

Reviewed by: M. Mergili and one anonymous referee

\section{References}

Abatzoglou, J. T. and Kolden, C. A.: Relationships between climate and macroscale area burned in the western United States, Int. J. Wildland Fire, 22, 1003-1020, 2013.

Ager, A. A., Finney, M. A., Kerns, B. K., and Maffei, H.: Modeling wildfire risk to northern spotted owl (Strix occidentalis caurina) habitat in Central Oregon, USA, Forest Ecol. Manag., 246, 4556, 2007.

Ager, A. A., Vaillant, N. M., and Finney, M. A.: Integrating fire behavior models and geospatial analysis for wildland fire risk assessment and fuel management planning, J. Combust., 19, 572452, doi:10.1155/2011/572452, 2011.

Ager, A. A., N. M. Vaillant, M. A. Finney, and H. K. Preisler: Analyzing wildfire exposure and source-sink relationships on a fire prone forest landscape, Forest Ecol. Manag., 267, 271-283, 2012.

Ager, A. A., Day, M. A., Finney, M. A., Vance-Borland, K., and Vaillant, N. M.: Analyzing the transmission of wildfire exposure on a fire-prone landscape in Oregon, USA, Forest Ecol. Manag., 334, 337-390, 2014.

Alcasena, F. J., Salis, M., Ager, A. A., Arca, B., Molina, D., and Spano, D.: Assessing landscape scale wildfire exposure for highly valued resources in a Mediterranean area, Environ. Manage., 55, 1200-1216, 2015.

Alonso-Betanzos, A., Fontenla-Romero, O., Guijarro-Berdiñas, B., Hernández-Pereira, E., Inmaculada Paz Andrade, M. A., Jiménez, E., Luis Legido Soto, J., and Carballas, T.: An intelligent system for forest fire risk prediction and fire fighting management in Galicia, Expert. Syst. Appl., 25, 545-554, 2003.

Athanasis, N., Kalloniatis, C., Vaitis, M., Vasilakos, C., and Kalabokidis, K.: Building an innovative solution for wildfire prevention and management: the "AEGIS" platform, in: EMCIS 2015: 12th European Mediterranean \& Middle Eastern Conference on Information Systems, Athens, Greece, 1-16, 2015 a.

Athanasis, N., Karagiannis, F., Palaiologou, P., Vasilakos, C., and Kalabokidis, K.: AEGIS App: Wildfire Information Management for Windows Phone Devices, Proced. Comput. Sci., 56, 544-549, $2015 b$.

Attiwill, P. and Binkley, D.: Exploring the mega-fire reality: A "Forest Ecol. Manag.” conference, Forest Ecol. Manag., 294, 1-3, 2013.

Burgan, R. E.: Revisions to the 1978 National Fire-Danger Rating System, USDA, Research Paper SE-273, Southeastern Forest Experiment Station, Asheville, NC, USA, 39 pp., 1988.

Caballero, D.: FOMFIS: A computer-based system for forest fire prevention planning, in: 3rd International Conference on Forest Fire Research, edited by: Viegas, D. X., ADAI, 16-20 November 1998, Luso, Portugal, 2643-2652, 1998.

Calkin, D. E., Thompson, M. P., Finney, M. A., and Hyde, K. D.: A Real-Time Risk Assessment Tool Supporting Wildland Fire Decisionmaking, J. Forest., 109, 274-280, 2011.

Corgnati, L., Gabella, M., and Perona, G.: FIREcast systemprevisional fire danger index computation system for alpine regions, in: First International Conference on Modelling, Monitoring and Management of Forest Fires (FIVA 2008), edited by: Heras, J., Brebbia, C., Viegas, D., and Leone, V., WIT Press, Toledo, Spain, 71-80, 2008.

Cruz, M. G., Sullivan, A. L., Gould, J. S., Sims, N. C., Bannister, A. J., Hollis, J. J., and Hurley, R. J.: Anatomy of a catastrophic wild- 
fire: The Black Saturday Kilmore East fire in Victoria, Australia, Forest Ecol. Manag., 284, 269-285, 2012.

EEA: Corine land cover update 2000 - Technical guidelines, Copenhagen, 56 pp., 2002.

Figueras Jové, J., Fonseca i Casas, P., Guasch Petit, A., and Casanovas, J.: FireFight: A Decision Support System for Forest Fire Containment, in: Improving Disaster Resilience and Mitigation - IT Means and Tools, NATO Science for Peace and Security Series C: Environmental Security, edited by: Teodorescu, H.-N., Kirschenbaum, A., Cojocaru, S., and Bruderlein, C., Springer, the Netherlands, 293-305, 2014.

Finney, M. A.: FARSITE: Fire area simulator-model development and evaluation. Res. Pap. RMRSRP-4, USDA Forest Service, Rocky Mountain Research Station, Ogden, UT, 1998.

Finney, M. A.: Design of Regular Landscape Fuel Treatment Patterns for Modifying Fire Growth and Behavior, Forest Sci., 47, 219-228, 2001.

Finney, M. A.: Fire growth using minimum travel time methods, Can. J. Forest Res., 32, 1420-1424, 2002.

Finney, M. A.: An overview of FlamMap fire modeling capabilities, in: Fuels Management - How to Measure Success, edited by: Andrews, P. L. and Butler, B. W., USDA Forest Service, Rocky Mountain Research Station, 28-30 March 2006, Portland, OR, 213-220, 2006.

Finney, M. A., Grenfell, I. C., McHugh, C. W., Seli, R. C., Trethewey, D., Stratton, R. D., and Brittain, S.: A method for ensemble wildland fire simulation, Environ. Model. Assess., 16, 153-167, 2011a.

Finney, M. A., McHugh, C. W., Grenfell, I. C., Riley, K. L., and Short, K. C.: A simulation of probabilistic wildfire risk components for the continental United States, Stoch. Env. Res. Risk A., 25, 973-1000, 2011b.

Forestry Canada Fire Danger Group: Development and structure of the Canadian Forest Fire Behavior Prediction System, Information Report ST-X-3, Forestry Canada, Ottawa, Ontario, 64 pp., 1992.

Gebert, K. M., Calkin, D. E., and Yoder, J.: Estimating Suppression Expenditures for Individual Large Wildland Fires, West. J. Appl. For., 22, 188-196, 2007.

Gumusay, M. U. and Sahin, K.: Visualization of forest fires interactively on the internet, Sci. Res. Essays, 4, 1163-1174, 2009.

Iliadis, L. S.: A decision support system applying an integrated fuzzy model for long-term forest fire risk estimation, Environ. Modell. Softw., 20, 613-621, 2005.

Janjić, Z. I.: The Step-Mountain Eta Coordinate Model: Further Developments of the Convection, Viscous Sublayer, and Turbulence Closure Schemes, Mon. Weather Rev., 122, 927-945, 1994.

Kalabokidis, K.: Automated forest fire and flood hazard protection system. Disaster management: linking people and the environment, Geoinformatics, 7, 14-17, 2004.

Kalabokidis, K., Xanthopoulos, G., Moore, P., Caballero, D., Kallos, G., Llorens, J., Roussou, O., and Vasilakos, C.: Decision support system for forest fire protection in the Euro-Mediterranean region, Eur. J. Forest Res., 131, 597-608, 2012.

Kalabokidis, K., Athanasis, N., Gagliardi, F., Karayiannis, F., Palaiologou, P., Parastatidis, S., and Vasilakos, C.: Virtual Fire: A web-based GIS platform for forest fire control, Ecol. Inform., 16, 62-69, 2013a.
Kalabokidis, K., Athanasis, N., Vasilakos, C., and Palaiologou, P.: Cloud Computing in Geospatial Analysis of Wildfire Danger and Fire Growth, in: 4th Fire Behavior and Fuels Conference "At the Crossroads: Looking Toward the Future in a Changing Environment", edited by: Wade, D. D. and Fox, R. L., 1-4 July 2013, International Association of Wildland Fire, St. Petersburg, Russia, 457-467, 2013b.

Kalabokidis, K., Palaiologou, P., and Finney, M. A.: Fire Behavior Simulation in Mediterranean Forests Using the Minimum Travel Time Algorithm, in: 4th Fire Behavior and Fuels Conference "At the Crossroads: Looking Toward the Future in a Changing Environment", edited by: Wade, D. D. and Fox, R. L., 1-4 July 2013, International Association of Wildland Fire, St. Petersburg, Russia, 468-492, 2013c.

Kalabokidis, K., Athanasis, N., Palaiologou, P., Vasilakos, M., Finney, M. A., and Ager, A. A.: Minimum travel time algorithm for fire behavior and burn probability in a parallel computing environment, in: 7th International Conference on Forest Fire Research, Advances in Forest Fire Research, edited by: Viegas, D. X., 17-20 November 2014, Coimbra University Press, Coimbra, Portugal, 882-891, 2014a.

Kalabokidis, K., Athanasis, N., Vasilakos, C., and Palaiologou, P.: Porting of a wildfire risk and fire spread application into a cloud computing environment, Int. J. Geogr. Inf. Sci., 28, 541-552, 2014b.

Kalabokidis, K., Palaiologou, P., and Athanasis, N.: A fire effects index for overall assessment of wildfire events in Greece, in: 7th International Conference on Forest Fire Research, Advances in Forest Fire Research, edited by: Viegas, D. X., 17-20 November 2014, Imprensa da Universidade de Coimbra, Coimbra, Portugal, 1600-1614, 2014c.

Kalabokidis, K., Palaiologou, P., Gerasopoulos, E., Giannakopoulos, C., Kostopoulou, E., and Zerefos, C.: Effect of Climate Change Projections on Forest Fire Behavior and Values-at-Risk in Southwestern Greece, Forests, 6, 2214-2240, 2015.

Kallos, G., Nickovic, S., Papadopoulos, A., Jovic, D., Kakaliagou, O., Misirlis, N., Boukas, L., Mimikou, N., Sakellaridis, G., and Papageorgiou, J.: The regional weather forecasting system SKIRON: An overview, in: International Symposium on Regional Weather Prediction on Parallel Computer Environments, 15-17 October 1997, Athens, Greece, 109-122, 1997.

Kaloudis, S., Costopoulou, C. I., Lorentzos, N. A., Sideridis, A. B., and Karteris, M.: Design of forest management planning DSS for wildfire risk reduction, Ecol. Inform., 3, 122-133, 2008.

Knight, I. and Coleman J.: A fire perimeter expansion algorithm based on Huygens' wavelet propagation, Int. J. Wildland Fire, 3. 73-84, 1993.

Kohonen, T.: Self-organized formation of topologically correct feature maps, Biol. Cybern., 43, 59-69, 1982.

Lee, B. S., Alexander, M. E., Hawkes, B. C., Lynham, T. J., Stocks, B. J., and Englefield, P.: Information systems in support of wildland fire management decision making in Canada, Comput. Electron. Agr., 37, 185-198, 2002.

Losso, A., Corgnati, L., Bertoldo, S., Allegretti, M., Notarpietro, R., and Perona, G.: SIRIO: an integrated forest fire monitoring, detection and decision support system-performance and results of the installation in Sanremo (Italy), in: Modelling, Monitoring and Management of Forest Fires III, edited by: Perona, G. and 
Brebbia, C. A., WIT Transactions on Ecology and The Environment, Southhampton, UK, 79-90, 2012.

McDaniel, J.: When things get busy: FSPro and RAVAR, http://www.wildfirelessons.net/HigherLogic/System/

DownloadDocumentFile.ashx?DocumentFileKey= a49c24cd-9f62-465f-a569-f2eb22dda953, last access: 24 January 2016.

McHugh, C. W.: Considerations in the use of models available for fuel treatment analysis, in: Fuels Management-How to Measure Success, edited by: Andrews, P. L. and Butler, B. W., Proceedings RMRS-P-41. USDA, Forest Service, Rocky Mountain Research Station, Fort Collins, CO, 81-105, 2006.

Miller, C. and Ager, A. A.: A review of recent advances in risk analysis for wildfire management, Int. J. Wildland Fire, 22, 1$14,2013$.

Noonan-Wright, E. K., Opperman, T. S., Finney, M. A., Zimmerman, G. T., Seli, R. C., Elenz, L. M., Calkin, D. E., and Fiedler, J. R.: Developing the US Wildland Fire Decision Support System, J. Combust., 14, 168473, doi:10.1155/2011/168473, 2011.

Palaiologou, P., Kalabokidis, K., and Kyriakidis, P.: Forest mapping by geoinformatics for landscape fire behaviour modelling in coastal forests, Greece, Int. J. Remote Sens., 34, 4466-4490, 2013.

Peterson, S. H., Morais, M. E., Carlson, J. M., Dennison, P. E., Roberts, D. A., Moritz, M. A., and Weise, D. R.: Using HFire for spatial modeling of fire in shrublands, Research Paper PSW-RP259, USDA Forest Service, Pacific Southwest Research Station, Albany, CA, 44 pp., 2009.

Prechelt, L.: Early Stopping - But When?, in: Neural Networks: Tricks of the Trade, Lecture Notes in Computer Science, edited by: Orr, G. and Müller, K.-R., Springer, Berlin, Heidelberg, 5569, 1998.

Rumelhart, D., Hinton, G., and Williams, R.: Learning representations by back-propagating errors, Nature, 323, 533-538, 1986.

Salis, M., Ager, A., Arca, B., Finney, M. A., Bacciu, V., Duce, P., and Spano, D: Assessing exposure of human and ecological values to wildfire in Sardinia, Italy, Int. J. Wildland Fire, 22, 549565,2013

Salis, M., Ager, A. A., Alcasena, F. J., Arca, B., Finney, M. A. Pellizzaro, G., and Spano, D: Analyzing seasonal patterns of wildfire exposure factors in Sardinia, Italy, Environ. Monit. Assess., 187, $1-20,2015$

San-Miguel-Ayanz, J., Barbosa, P., Schmuck, G., Liberta, G., and Schulte, E.: Towards a coherent forest fire information system in Europe: the European Forest Fire Information System (EFFIS), in: IV International Conference on Forest Fire Research, edited by: Viegas, D., 18-23 November 2002, Millpress Science Publishers, Luso, Coimbra, Portugal, 5-16, 2002.
Scott, J. H., Thompson, M. P., and Calkin, D. E.: A wildfire risk assessment framework for land and resource management. General Technical Report RMRS-GTR-315, USDA, Forest Service, Rocky Mountain Research Station, Fort Collins, CO, 83 pp., 2013.

Stratton, R. D.: Guidance on spatial wildland fire analysis: models, tools, and techniques. General Technical Report RMRS-GTR183, USDA, Forest Service, Rocky Mountain Research Station, Fort Collins, CO, 15 pp., 2006.

Taylor, S. W., Pike, R., and Alexander, M. E. (Eds.): Field guide to the Canadian Forest Fire Behavior Prediction (FBP) System (BINDER), Natural Resources, Canada, Canadian Forest Service, Northern Forestry Centre, Edmonton, AB, 1997.

Tsekouras, G. E., Manousakis, A., Vasilakos, C., and Kalabokidis, K.: Improving the effect of fuzzy clustering on RBF network's performance in terms of particle swarm optimization, Adv. Eng. Softw., 82, 25-37, 2015.

Vakalis, D., Sarimveis, H., Kiranoudis, C., Alexandridis, A., and Bafas, G.: A GIS based operational system for wildland fire crisis management I. Mathematical modelling and simulation, Appl. Math. Model., 28, 389-410, 2004.

Van Wagner, C. E.: Development and structure of the Canadian Forest Fire Weather Index System, Forest Technical Report 35, Canadian Forest Service, Ottawa, Ontario, 35 pp., 1987.

Vasilakos, C., Kalabokidis, K., Hatzopoulos, J., Kallos, G., and Matsinos, Y.: Integrating new methods and tools in fire danger rating, Int. J. Wildland Fire, 16, 306-316, 2007.

Vasilakos, C., Kalabokidis, K., Hatzopoulos, J., and Matsinos, I.: Identifying wildland fire ignition factors through sensitivity analysis of a neural network, Nat. Hazards, 50, 125-143, 2009.

Viney, N. R: A review of fine fuel moisture modelling. Int. J. Wildland Fire, 1, 215-234, 1991.

Williams, J.: Exploring the onset of high-impact mega-fires through a forest land management prism, Forest Ecol. Manag., 294, 4-10, 2013.

Zachariassen, J., Zeller, K. F., Nikolov, N., and McClelland, T.: A review of the Forest Service Remote Automated Weather Station (RAWS) network, General Technical Report RMRS-GTR-119, USDA Forest Service, Rocky Mountain Research Station, Fort Collins, CO, 153 pp., 2003. 